\title{
La continencia de la causa vs. el libre desarrollo de la personalidad. EI divorcio incausado en Veracruz*
}

\author{
Irvin Uriel López Bonilla** \\ Mitchell Sarahí Zapata Durán***
}

RESUMEN: La ecuación: diversidad de prestaciones - identidad de personas y cosas - un solo procedimiento - una sola sentencia, ha permanecido inamovible durante años en pretexto de la configuración de la continencia de la causa, sin la existencia de una norma que sustente la inflexibilidad con la que se ha aplicado. De cara al derecho humano al libre desarrollo de la personalidad, esta práctica reiterada debe doblegarse en favor del accionante del divorcio incausado, cuyo plan de vida se obstaculiza a causa de la inexorable búsqueda de una sola sentencia definitiva que resuelva las múltiples pretensiones con nexos a la disolución del vínculo matrimonial, sujetas a la temporalidad infructuosa del proceso. Por lo que, en el manuscrito, presentamos la carga argumentativa de contrapeso a lo expuesto por un órgano de control constitucional que, en su labor jurisdiccional, sobrepone la figura procesal de la continencia de la causa al ejercicio pleno del libre desarrollo de la personalidad.
ABSTRACT: The equation: diversity of legal benefits - personal and acts identity - a single procedure - only one verdict, it has been immovable for years under the pretext of shaping the continence of the cause, without the existence of a rule that supports the inflexibility with which it has been applied. In front to the human right to the free development of the personality, this reiterated practice must bend in favor of the plaintiff of the divorce without cause, whose life plan is hindered due to the inexorable search for a only one veredict that resolves all claims related to the dissolution of the marriage bond subject to the unsuccessful temporality of the process. Therefore, in this manuscript, we present the argumentative burden of counterbalance to the exposed by a constitutional control body that, in its jurisdictional work it imposes the procedural figure of the continence of the cause to the full exercise of the free development of the personality.

\footnotetext{
* Artículo recibido el $1^{\circ}$ de mayo de 2020 y aceptado para su publicación el 25 de mayo de 2020.

** Licenciado en Derecho y Maestro en Derechos Humanos y Justicia Constitucional por la Universidad Veracruzana. Co-coordinador de la Clínica de litigio estratégico transformaciones jurídicas de la misma Casa de Estudios.

*** Licenciada en Derecho por la Universidad Veracruzana; Maestra y Doctora en Derecho Procesal por el Centro Mexicano de Estudios de Posgrado.
} 
López I. y Zapata M. / La continencia de la causa vs. el libre desarrollo de la personalidad. El divorcio incausado en Veracruz

Palabras clave. Continencia de la causa, divorcio incausado, libre desarrollo de la personalidad, proceso civil, sentencia definitiva.
Keywords. Continence of the cause, divorce without cause, free development of the personality, civil prosecution, definitive veredict.

SUMARIO: Introducción. 1. La continencia de la causa: entre su aplicación inexcusable y la necesidad de su fraccionamiento. 2. Tratamiento del libre desarrollo de la personalidad en el sistema jurídico mexicano. 3. La tramitación jurisdiccional del divorcio incausado en Veracruz, a propósito de la anteposición de la continencia de la causa al libre desarrollo de la personalidad. Notas críticas. Conclusiones. Fuentes de consulta.

\section{Introducción}

La labor de los operadores jurisdiccionales ha jugado un papel importante ante la anarquía que experimentan diversas normas locales del sistema jurídico mexicano. Si bien, el problema pudiera redundar en la falta de reconocimiento de diversas figuras procesales y la renuencia de las legislaturas de actualizar las ya existentes, para volver asequible el contenido próximo de derechos humanos, lo cierto es que, resulta más grave cuando su exigibilidad y justiciabilidad se presume en manos de un juzgador que, lejos de cumplir con ser "El Juez Hércules", se convierte en su depredador.

Aunque pareciera que esta realidad es paralela a la nuestra y que todos los operadores se encuentran comprometidos con la satisfacción de derechos humanos, acatando los mandamientos constitucionales de su promoción, protección, respeto y garantía, existen criterios judiciales que impiden la satisfacción de los mínimos indispensables de un derecho, pese a tratarse de un coto vedado, como el libre desarrollo de la personalidad.

Con esa base, nos hemos visto en la necesidad de exponer lo que a nuestro juicio es una posición judicial atávica, alejada de la sana crítica y de la permeabilidad de los nuevos estándares de protección de derechos humanos, porque sacrifica el libre desarrollo de la personalidad frente a un formulismo procesal, que debe advertir otras lecturas.

Por ello, con el objetivo de discernir sobre un criterio específico materializado en una resolución jurisdiccional que adquirió el grado de tesis aislada, nos hemos propuesto dividir el trabajo en tres apartados. En el primero, trazamos las bases de la continencia de la causa para ahondar sobre la viabilidad de su fraccionamiento y sustentar el por qué pueden justificarse una variedad de sentencias definitivas que cumplan con la materialidad de resolver los puntos principales controvertidos. En el segundo, punteamos el tratamiento que en la doctrina y en la jurisprudencia mexicanas, se ha dado al derecho humano al libre desarrollo de la personalidad. Y en el tercero, describimos las necesidades de armonización legislativa en Veracruz, el problema sobre el que transita la tramitación jurisdiccional del proceso de divorcio incausado y los resultados obtenidos y, realizamos algunas notas críticas en función del criterio abordado por un Tribunal Colegiado de Circuito en Materia Civil, en Veracruz.

Metodológicamente, aplicamos el respectivo hipotético-deductivo porque partimos del asidero que tiene la figura de la continencia de la causa como ente que finalmente busca 
proteger el derecho a la tutela jurisdiccional efectiva, transitamos por el contenido del derecho al libre desarrollo de la personalidad como derecho potencialmente infringido y concretamos en un criterio abordado por el Primer Tribunal Colegiado en Materia Administrativa del Séptimo Circuito, contra argumentando a partir de lo resuelto por la propia Suprema Corte de Justicia de la Nación (SCJN). También aplicamos los métodos exegético y sistemático, al realizar un examen del andamiaje regulatorio, interrelacionado con el cuerpo normativo con una visión geográfica de la institución procesal estudiada: la continencia de la causa. Y, por último, el método dogmático, al atender doctrina y criterios jurisdiccionales que han servido de base para dotar de sentido, significado y alcance a los derechos estudiados.

Se ha implementado y por lo tanto creído indudablemente, a través de la doctrina y su práctica, que en un proceso complejo por cuanto al número de pretensiones, solo puede existir una sentencia definitiva que resuelva todos los puntos de litigio, porque así se garantiza la tutela jurisdiccional efectiva, materializada a través de la continencia de la causa. No obstante, los nuevos estándares en materia de derechos humanos, demandan que las fórmulas procesales sean replanteadas herméneuticamente con las condiciones más favorables para quien acude a un sistema procesal en búsqueda de satisfacer el contenido de sus derechos. De ahí que propongamos que en el polinomio integrado por un proceso con identidad de hechos, cosas y personas, se proyecte la mutabilidad del arquetipo de la sentencia definitiva a su pluralidad, porque así puede sesgarse al cumplimiento de protección, respeto y garantía de derechos humanos, siempre bajo un orden cualitativo y no cuantitativo del ordenamiento constitucional.

\section{La continencia de la causa: entre su aplicación inexcusable y la necesidad de su fraccionamiento}

El diseño arquitectónico del derecho procesal abarca un tronco común que luego se divide en ramas particulares (Ovalle, 1981: 20), sin embargo, en su basamento son coincidentes. En la estructura más básica, un proceso involucra el derecho de acción, el derecho de excepción, las formalidades del procedimiento, la resolución del diferendo y su ejecución. Inclusive, en esencia representa la satisfacción del derecho humano a la tutela judicial efectiva, por lo que, si hablamos de derecho procesal, no podemos soslayar lo que implica el derecho fundamental a la que obedece, sobre todo a sabiendas que las normas procedimentales -adjetivas- observan como sentido a las denominadas sustantivas para formar una cadena de destino-destinatario (Briseño, 2016: 205).

El derecho de tutela judicial efectiva que -guardadas proporciones-se podría satisfacer mediante un adecuado proceso judicial, obliga a que en sus etapas se garantice la protección de otros derechos interrelacionados -autónomos pero, interdependientes- a través de una reglamentación razonable, como si de un juego de frenos y contrapesos se tratara, ubicados en diferentes momentos: antes, durante y después de concluido el proceso. Visto de esa manera, el término proceso judicial no es menor, porque en realidad representa la forma natural de garantizar la tutela jurisdiccional como su fin último e inmiscuido en él, otros tantos derechos. 
Los subconjuntos de derechos interconectados con la tutela judicial efectiva, los podemos visualizar en la siguiente tabla (Primera Sala de la SCJN, 2017: 151; Pleno de la SCJN, 1995: 193):

\begin{tabular}{|c|c|c|c|}
\hline DERECHO & \multicolumn{3}{|c|}{ Tutela jurisdiccional efectiva } \\
\hline ETAPA & Previa al juicio & $\begin{array}{c}\text { Judicial } \\
\text { Comprende desde el inicio del } \\
\text { procedimiento hasta la última actuación }\end{array}$ & Posterior al juicio \\
\hline SUBDERECHOS & 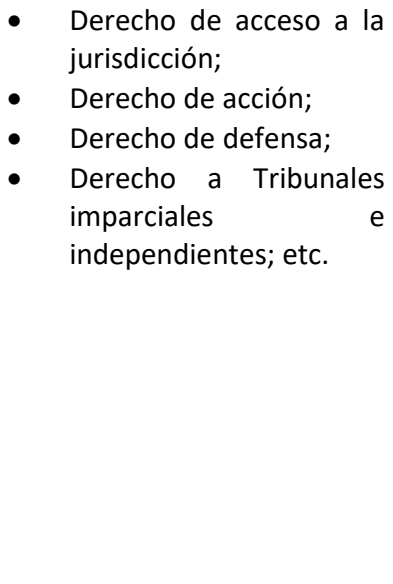 & 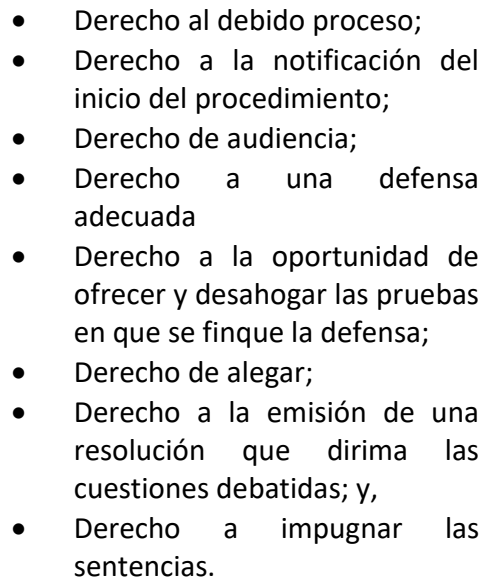 & $\begin{array}{l}\text { - Derecho a la eficacia } \\
\text { de las resoluciones; } \\
\text { Derecho al } \\
\text { cumplimiento de las } \\
\text { sentencias; etc. }\end{array}$ \\
\hline
\end{tabular}

Tabla 1. Derechos interconectados con la tutela judicial efectiva. Elaboración propia con información de criterios de la SCJN.

En la tabla anterior podemos destacar gráficamente las tres etapas que componen el gran paraguas ${ }^{1}$ que representa la tutela jurisdiccional efectiva. Nos ubicaremos particularmente en la segunda, la judicial. En esta, se describen diversas prerrogativas que, sin ánimo de exclusión, resultan ser verdaderos derechos humanos autónomos, con asidero constitucional y convencional, pero articulados para satisfacer el núcleo del derecho a la tutela judicial. Esta articulación implica el diseño de instituciones y reglas operativas que rijan un procedimiento, que de suyo no resultan inconstitucionales si se ajustan a criterios idóneos, necesarios, razonables y proporcionales o, de cuya aplicación no dimane un exceso procesal injustificado.

La labor del legislador es establecer las reglas del juego, es decir, imponer plazos, términos, requisitos, condiciones, presupuestos y cualquier otra categoría para la efectividad del procedimiento. De cara a ello, el juzgador adquiere una figura de dirección, con competencias incluso para inaplicar normas que pudieran devenir en un menoscabo de derechos humanos, por la ejecución inflexible de pautas procesales innecesarias e irrazonables o para preferir -hermenéuticamente- entre las lecturas de una norma, la que resulte menos lesiva o más protectora a los justiciables.

Dentro del género de las instituciones y requisitos procesales destaca para nuestro objeto de estudio la continencia de la causa, que significa la unidad jurídica y cuya

\footnotetext{
${ }^{1}$ El término paraguas lo hemos empleado denotando que la tutela jurisdiccional efectiva es un derecho humano que abarca una gran variedad de derechos autónomos, que no obstante de serlo, se encuentran interconectados con el primero.
} 
materialización se ha orientado en la segunda etapa de la que hablábamos supra, específicamente en el subderecho a la emisión de una resolución que dirima las cuestiones debatidas, aunque esa solo es una de las razones a las que obedece su existencia. Si partimos de la idea de que la continencia de la causa significa la unidad procesal, entonces nos conviene puntualizar que gramaticalmente el término unidad, siguiendo el Diccionario de la Real Academia Española, significa "1. f. Propiedad de todo ser, en virtud de la cual no puede dividirse sin que su esencia se destruya o altere" (RAE, 2019: párr. 1), por lo que inmediatamente endosa la idea de una intransigente indivisibilidad, ya que, al hacerlo, perdería la propiedad para la cual fue diseñada. Aunque ello debe ser matizado.

Esta premisa procesal se justifica de varias y diversas medidas. Constitucionalmente, porque dota de certidumbre jurídica al cumplir con la congruencia de fundar y motivar todo acto de molestia, como lo mandatan los artículos 14 y 16 de la Constitución Política de los Estados Unidos Mexicanos (CPEUM). Teleológicamente, porque permite que en un solo procedimiento se ventilen una multiplicidad de acciones generadas con identidad de hechos, cosas y personas, sin que se extreme en el grado de litisconsorcio, generando que quienes intervienen obtengan una sola resolución que evite que, de resultar varias, se contrapongan. Y procesalmente, porque resulta económico al procedimiento, dirimir los puntos litigiosos planteados en una sola sentencia.

Ahora bien, lo descrito engendra la regla general que, también admite excepciones o lecturas diversas. Aunque sobre ello volveremos más tarde, por lo que aquí interesa, debemos colocar el dedo en que la continencia de la causa es la idea de la acumulación de acciones; producida por la naturaleza de la indivisibilidad y la consecuente necesidad de resolver los puntos controvertidos de un proceso en una sola sentencia; y, que puede devenir at initio o en el interprocesal. La segunda opción, materialmente se conoce como acumulación de autos, con las amplias posibilidades de identidades en personas, acciones o cosas, siempre que de alguna manera converjan. Empero, nos situaremos en la continencia de la causa que se suscita cuando las mismas personas -litigantes- se exigen una pluralidad de acciones, cuya naturaleza permite ser conocidas en un solo proceso.

Pese a que la continencia de la causa es una figura procesal que irradia efectos sobre todas las áreas de la ciencia jurídica, nos ceñiremos únicamente a la regulación en el derecho procesal civil veracruzano, para sentar las bases estructurales sobre la acción del divorcio y las consecuencias de la disolución del vínculo matrimonial.

De una interpretación sistemática entre los artículos 4 y 21 el Código de Procedimientos Civiles para el Estado de Veracruz (CPCV), tenemos que, cuando a quien competa ejercer una acción, por sí o a través del que legalmente lo represente, lo realice y existan pluralidad de prestaciones que se desprendan de la misma causa y tengan el mismo objeto, la acción será intentada mediante una sola demanda, es decir, se postulará en un solo procedimiento. En esa premisa normativa, se tiene por satisfecha la procedencia de la continencia de la causa en su modalidad ad initio.

Esa situación se robustece cuando el código adjetivo se refiere al acto procesal de las sentencias. En el diverso 56, se irroga que las sentencias tienen la naturaleza de resoluciones judiciales que, a diferencia de los autos y decretos, deciden el asunto principal 
controvertido; mediante estas, se deberán decidir todos los puntos litigiosos que hayan sido objeto del debate, dando resolución correspondiente a cada uno de ellos - artículo 57 -.

Lo último, constituye lo que en la teoría se ha denominado congruencia y que advierte dos modalidades. La primera denominada congruencia externa, que significa la concordancia con la demanda y con la contestación y, la segunda, la congruencia interna, que implica la armonía entre las mismas partes de la sentencia (Tribunales Colegiados de Circuito, 1997: 813).

Sin embargo, la congruencia externa a la que hacemos referencia, debe convenirse con todas las actuaciones procesales que obren en el juicio y dejar de constreñirse únicamente a los dos escritos iniciales a los que nos referimos líneas arriba, porque a pesar de que en esos dos ocursos se sitúa el objeto del juicio, lo cierto es que de ello se pueden desprender pretensiones, que por su previa y especial naturaleza deban preponderarse sobre los requisitos procesales y resolverse previo a una única sentencia que resuelva todos los puntos objeto de litigio. Más, si destacamos que de la literalidad del artículo 57 del CPCV se desprende que, las sentencias -en plural-deben decidir todos los puntos litigiosos que se encuentren sub judice, sin que se refiera que sea en una sola sentencia en la que se resuelvan, esto es, el legislador no distingue en qué momento debe existir el pronunciamiento sobre todos los puntos controvertidos o bajo qué naturaleza de la tipología de las sentencias deba hacerse y, que incluso, para dar efectividad al proceso, pueda escindirse la continencia de la causa.

Lo aseverado concuerda con la multiplicidad de sentencias que pueden dictarse en un procedimiento y que de alguna manera se relacionan con el objeto del juicio que se haya planteado mediante los escritos de demanda y de contestación. Veamos por qué.

Partamos de que una sentencia es una norma jurídica individualizada porque se refiere a situaciones concretas o particulares, mediante la cual se constituyen o se declaran derechos u obligaciones para sujetos determinados, cuya formación requieren de ciertos requisitos de validez, en su caso, de transitar una secuela procesal tazada para el efecto (Jongitud, 2012: 114). Ahora, el proceso está situado en el desarrollo de un cúmulo de procedimientos que deben agotarse para obtener diferendos, ya sea en su carácter de definitivos o interlocutorios. La doctrina ha sostenido que las sentencias definitivas son aquellas que ponen fin a un proceso, mientras que las interlocutorias deciden cuestiones procedimentales que tienen que ser determinadas antes de llegar al momento de la definitiva (Rumoroso, 2013: 4).

En el caso de las sentencias interlocutorias, el CPCV admite diversos supuestos en que pueden configurarse, por ejemplo, cuando se determina la incompetencia por declinatoria -artículo 26-, cuando se resuelve la recusación -artículo 144-, cuando se falla en materia de alimentos provisionales - artículo162-, cuando se trata de excepciones supervenientes - artículo 222-o, cuando se refiere al reconocimiento o inspección judicial -artículo 279-, también se permite decidir en esta naturaleza los recursos o los incidentes, tramitados dentro del mismo o por cuerda separada. Lo anterior da cuenta de la capacidad del juzgador de pronunciarse sobre cuestiones que no pueden esperar al pronunciamiento de las 
sentencias definitivas. Aunque a diferencia de estas, aquellas no deciden cuestiones de fondo, sino procedimentales.

Los apuntes hechos son coincidentes con lo resuelto en la Contradicción de Tesis 104/2019 (Primera Sala de la SCJN, 2019). El Alto Tribunal sostuvo que de un ejercicio hermenéutico sistemático-jurídico-teleológico de las reglas y principios de la acumulación de acciones, se podía sostener que el juez tiene atribuciones para escindir, separar o desacumular un proceso que contenga varias pretensiones (: 28), porque, por principio de cuentas, no existe disposición alguna que lo prohíba y, en segunda, porque la posibilidad de escisión de acciones está enfrascada en todos y cada uno de los sistemas procesales que contemplen la probabilidad $u$ obligación de acumular diversas pretensiones en una demanda, amén de que la finalidad de tal figura es la economía procesal y la seguridad jurídica al evitar fallos contradictorios (:29).

De esa manera, cuando la “(...) unión no esté dando el resultado pretendido (...) generando (...) dirección opuesta a la del principio de economía procesal, llevando una tramitación más embarazosa que la sustanciación individual (...)” (: 55) y, cuando ya no exista el riesgo de obtener sentencias contradictorias en virtud del examen de constancias de autos, irrogando en el juez la obligación de tomar las medidas necesarias para el resguardo de los principios y valores inmiscuidos en el proceso, evitando gravámenes no deseados previa vista que se haga a las partes (: 55), debe preferirse el fraccionamiento de la continencia de la causa. A mayoría de razón, advierte la SCJN, cuando de la aplicación estricta de la acumulación se vulneren principios constitucionales (: 55).

En esa medida, la continencia de la causa como una figura procesal, debemos entenderla en un ánimo de procuración, es decir, el juzgador debe tratar de mantener la unidad jurídica, sin que ello implique que esta no pueda dividirse o fraccionarse, cuando en un orden cualitativo del derecho, su escisión sea necesaria para proteger derechos sustantivos inmiscuidos. Es una figura procesal cuya aplicabilidad admite excepciones, sobre todo si vemos al juez como un rector del proceso con obligación, incluso, de eliminar los obstáculos que pudieran comprometer la satisfacción del contenido de un derecho.

Si bien el juzgador debe garantizar las formalidades de un procedimiento, para dotar de certidumbre jurídica y, por vía de consecuencia, resguardar la tutela jurisdiccional, la unidad jurídica del litigio no se limita al dictado de una sentencia, porque para su cumplimiento es importante considerar la naturaleza de las acciones que forman el objeto del proceso y la gama de posibilidades que la propia ley ofrece, en este caso, el pronunciamiento de una variedad de sentencias que posibilitan el seccionamiento de la continencia de la causa, sin que ello implique sacrificar la justicia por la que una persona acude a un sistema procesal (ColDH, 2001: párr. 51), sobre todo, si tomamos en cuenta que el proceso civil y específicamente la persecución de la continencia de la causa, es de naturaleza rogada.

En otras palabras, la continencia de la causa es una de las instituciones procesales diseñadas para garantizar el ejercicio del derecho a la tutela jurisdiccional efectiva, que no es absoluto, por lo que su aplicación debe alejarse de un extremo riguroso, sino más bien de manera cualificativa, en aras de su necesidad. 


\section{Tratamiento del libre desarrollo de la personalidad en el sistema jurídico mexicano}

Con la reforma del 18 de junio de 2008 al artículo 19 de la CPEUM se acuñó el término libre desarrollo de la personalidad. Aunque esa referencia se hizo en materia penal, lo cierto es que por una visión geográfica, su incorporación permite entender una protección a la esfera vital de la persona, pues el menoscabo a este derecho a través de la perpetración de un delito grave hace procedente la prisión preventiva oficiosa. Ahora bien, podríamos estar o no de acuerdo con la ratio de la prisión preventiva, incluso cuestionarnos si es idónea la medida para la protección del derecho al libre desarrollo de la personalidad, pero al no ser nuestro objeto de estudio, la comparación la hacemos para extremar la importancia con la que el poder reformador visualizó este derecho.

Sin embargo, la inclusión del derecho no significa ipso facto su tutela y protección material, en realidad aunque no se debiera, como afirma Aguilera, las libertades públicas, como categorías prejurídicas abiertas y flexibles, requieren de desarrollos positivos en los ordenamientos jurídicos (2018: 199). De esta manera, el libre desarrollo de la personalidad no solo se podría ver afectado mediante la comisión de un delito -sea grave o no-, sino también por la ejecución u omisión de otros diversos actos, de particulares o entes públicos, que impidan a una persona ejercer su libertad de acción y de alternativas, dependiente de su particularidad como individuo, de manera que ese contenido ha tenido que ser terreno ganado en la incoación de su exigibilidad y justiciabilidad.

Dada la diversificación de escenarios a los que una persona se expone en su vida cotidiana, en los que necesariamente debe optar por alguna decisión individual, se multiplican los actos que pudieran menoscabar el libre desarrollo de la personalidad, de ahí que resulte su carácter multifacético; basado en la autonomía; con aparejamiento en las decisiones sobre su autodeterminación según su consciencia (Moral, 2012: 73); endosado como una consecuencia de la dignidad humana, cuyo entendimiento es insuficiente en un reduccionismo normativo y en una simplificación sinonímica del derecho a la igualdad y no discriminación (López, 2019: 170).

Ante tal premisa, la visión de dignidad, en la idea de que esta es engendrante del libre desarrollo de la personalidad, debe reconducirse a un carácter consustancial de las decisiones de cada persona en su individualidad, pues tal como afirma Lozano (2004) esas determinaciones son el fundamento de lo que significa ser persona (: 629); cuyo bien protegido es la vida misma (Vázquez, 2017: 4); que el papel que juega en el orden constitucional es de naturaleza normativa, proyectando sus efectos de un criterio orientador a una disposición vinculante (Hernández, 2018: 15). Esa fuerza obligatoria es convergente con la que la SCJN ha sostenido al definir a la dignidad como un principio y como un derecho fundamental que resulta “(...) ser la base y condición para el disfrute de los demás derechos y el desarrollo integral de la personalidad." (Primera Sala de la SCJN, 2016: 633).

Lozano (2004: 629) y Moral (2012: 73) concurren en que el núcleo de este derecho son las decisiones que, sobre sus actos, una persona toma durante su existencia, de conformidad con su modelo de vida, es decir, en palabras de Silva y Valls (2014), representa 
“(...) la consecución del proyecto de vida que para sí tiene cada ser humano, como ente autónomo" (:29) y que dispone acorde a sus valores, ideas, expectativas, gustos, etc. (Victoria, 2019: 39).

Eraña, por su parte, sostiene que el derecho de mérito accede como principio y valor fundante y subsidiario de cualquier libertad, garantizando la no interferencia o lesiones en su ejercicio (2014: 146), con lo que satisface la obligación del contexto -que incluye las otras personas que no son el que ejerce el derecho y los entes públicos- de no interferir en su praxis. No obstante, la responsabilidad estatal además de ese aspecto negativo, tiene uno positivo que se traduce en obligaciones de hacer. Por un lado, el Estado debe proporcionar los medios necesarios (Flores, 2019: 226) y, por otro, eliminar los obstáculos que se tengan administrativa, legislativa o judicialmente para garantizar su ejercicio.

La naturaleza jurídica del libre desarrollo de la personalidad supone: 1) Ubicarlo en la categoría de derechos individuales, por la titularidad correspondiente a la persona; 2) Puntuarlo en conexidad con otros derechos, no solo en su carácter de indivisible, sino por los efectos reales que consecuentan en la vida del titular; y, 3) Significa un derecho global, que envuelve a otros derechos como si fueran subconjuntos inmersos en el gran conjunto llamado libre desarrollo de la personalidad (Hernández, 2018: 5 y 6).

Concisamente los obstáculos que, ante la anarquía normativa se han devenido en la práctica del derecho al libre desarrollo de la personalidad, han sido paulatina pero efectivamente derribados en los Tribunales mexicanos, jugando así, un papel de suma trascendencia.

La SCJN, mediante la resolución del Amparo Directo Civil 6/2008, se pronunció por primera ocasión sobre el derecho al libre desarrollo de la personalidad y su conexidad con otros derechos (Eraña, 2014: 146). En la sentencia, señaló que este representa “(...) el reconocimiento del Estado sobre la facultad natural de toda persona a ser individualmente como quiere ser, sin coacción, ni controles injustificados o impedimentos por parte de los demás, con el fin de cumplir las metas u objetivos que se ha fijado (...)" (Primera Sala de la SCJN, 2009: 44). En realidad redujo sus alcances a la palabra decisión, pero también concordó con la doctrina, en el sentido de que dichas decisiones no son absolutas, como cualquier ejercicio de derechos humanos, por lo que los límites -justificados- son los derechos de terceros y el orden público (:45), sin que necesariamente la protección de terceros signifique una condición sostenible, a rajatabla, para sacrificar un derecho de tal envergadura, sobre todo a sabiendas que el libre desarrollo de la personalidad se vincula con otros derechos que impactan en el proyecto de vida cuyo daño es irreparable, en tanto que "(...) toda persona tiene derecho a vivir su propia vida y a desarrollarse como ella pretenda (...) con libertad (...)" (: 45). En esta suerte, un límite al libre desarrollo de la personalidad, para encontrarse cabalmente anidado, debe ser idóneo, necesario, justificado y proporcional.

En esa óptica, el libre desarrollo de la personalidad implica en su aspecto más elemental el ejercicio de la libertad, por lo que, las decisiones que contemple una persona para su vida, incluye, en la línea de la SCJN, la de contraer o no matrimonio; la de procrear, si es que lo desea hacer; la de escoger su apariencia personal; su alternativa profesional o laboral; la 
libre opción sexual; etc., que son aspectos de la esfera más próxima de la persona, que la definen y la proyectan en su vida de forma autónoma (:44).

Sin embargo, la sentencia a la que hacemos referencia fue solo la base. En fechas recientes, la SCJN retomó el contenido del derecho y amplió, de manera enunciativa pero no limitativa, el examen de las decisiones que lo enderezan, vr. gr., la restricción de disolver el vínculo matrimonial mediante la acreditación de causales de divorcio (Primera Sala de la SCJN, 2015: 570), el acceso a la educación básica (Primera Sala de la SCJN, 2017: 178) y el autoconsumo, incluso con fines lúdicos, de marihuana (Primera Sala de la SCJN, 2019: 489; Primera Sala de la SCJN, 2019: 493; Primera Sala de la SCJN, 2019: 496; Primera Sala de la SCJN, 2019: 1127).

En resumidas cuentas, no cabe posibilidad a duda que el libre desarrollo de la personalidad es un derecho sólido, de coto vedado, personalísimo, sujeto a una ecuación cuya expresión constante es la dignidad humana. En su configuración, podemos destacar dos extremos: uno interno y otro externo. El primero, se refiere justo a la esfera vital del individuo, la más próxima a su intimidad y autonomía, que implica las decisiones que de acuerdo a sus particularidades individuales tome para construir su proyecto de vida, lo que esa persona quiere ser y por qué lo quiere ser, $i$. e., su visualización interna, que puede ser desigual si se confronta con las de otras personas, incluso del mismo colectivo al que pertenezcan; $y$, por otro lado, el extremo externo compromete la posibilidad de que el ejercicio del derecho sea oponible a terceros, siempre que ello no resulte en un perjuicio a estos o confronte al orden público.

Es lógico que las decisiones que una persona tome para sí, pueden tener repercusiones hacia el colectivo al que pertenece o respecto a una persona directamente, sin embargo, cuando estas decisiones no infringen la del espacio vital del contexto, entonces la decisión adquiere protección constitucional.

Autónomamente, una persona en el ejercicio del libre desarrollo de la personalidad tiene la facultad de diseñar el proyecto de su vida y en consecuencia tomar en libertad, alternativamente, sin injerencia de otros o del propio poder público, las decisiones que considere lo llevarán a concretarlo. Pero esas decisiones están sujetas al respeto de la esfera jurídica de terceros y del orden público, con la debida justificación en la cesión que deba hacer un derecho frente a otro cuando resulten varios involucrados. Esto deberá atenderse de manera cualitativa, con las particularidades que envuelvan los derechos mezclados, indivisible e interdependientemente.

\section{La tramitación jurisdiccional del divorcio incausado en Veracruz, a propósito de la anteposición de la continencia de la causa al libre desarrollo de la personalidad. Notas críticas}

El Código Civil para el Estado de Veracruz de Ignacio de la Llave (CCV) data de 1932; su falta de armonización con los nuevos estándares de protección de derechos humanos ha ocasionado serias vejaciones al aplicar normas arcaicas a realidades evidentemente nuevas. Sabemos que una de las fuentes del derecho son las reales, como circunstancias que inspiran la creación de normas jurídicas (García, 2008: 53), sin embargo, en la entidad 
veracruzana, los legisladores han permanecido renuentes en adoptar las medidas legislativas que garanticen la protección efectiva de diversas prerrogativas, que de facto circundan en nuestra realidad.

La protección de la diversidad en la constitución de las familias, el derecho a la pensión compensatoria, el reconocimiento como contribución a la sociedad conyugal por la dedicación al cuidado del hogar y a la crianza de los hijos, la guarda y custodia compartida, el reconocimiento de la personalidad de las disidencias sexuales y el divorcio incausado, son algunos de los problemas de omisiones normativas -tanto sustantivas, como adjetivas- a las que nos enfrentamos cotidianamente en Veracruz.

Este panorama representa un estanque legislativo para el que la labor jurisdiccional ha sido fundamental. Mediante resoluciones judiciales se han sentado bases consolidadas para dar efectividad al contenido constitucional de derechos humanos, no obstante, ello se sujeta a la libertad de criterio de los operadores jurisdiccionales que, teniendo amplias facultades para fungir como directores del proceso judicial e incidir positivamente en el sentido, contenido, significado y alcance de un derecho, en muchas ocasiones anteponen formulismos procesales al núcleo de una prerrogativa humana, tal como sucedió en el Primer Tribunal Colegiado en Materia Civil del Séptimo Circuito, en materia de divorcio incausado y, del que hablaremos más adelante.

Por lo pronto recapitulemos en que, tanto la tutela jurisdiccional efectiva como el libre desarrollo de la personalidad son derechos de carácter global -tipo paraguas, como les denominamos anteriormente- cuyo ejercicio es interdependiente y compromete la garantía de otros derechos autónomos. La continencia de la causa, por su parte, es una medida procesal esbozada para preservar la tutela jurisdiccional, a través de la idea de la unidad jurídica, garantizando la economía procesal y la inexistencia de pluralidad de sentencias que resuelvan de forma diferente puntos de litigio con identidad de personas, acciones y cosas. En cambio, el libre desarrollo de la personalidad en su naturaleza de derecho humano, representa la práctica del diseño del proyecto de vida de una persona por el que se protegen las decisiones que se toman para su construcción.

En la coincidencia del derecho al libre desarrollo de la personalidad y la aplicación de la continencia de la causa, debemos delinear claramente el problema que experimentamos en el Estado de Veracruz ante la omisión del reconocimiento de la figura del divorcio incausado y los criterios de los juzgadores al resolver las acciones que se intentan y que convergen desde un hecho generador: el matrimonio y la voluntad de uno de los consortes de disolverlo.

En un plan genérico no redundaría mayor problema si el ejercicio de la acción de un cónyuge contra otro fuera únicamente la disolución del vínculo matrimonial, porque el punto controvertido sería exclusivamente la procedencia de la acción del divorcio. Ello puede originarse en asuntos en los que, imaginemos, los consortes contrajeron nupcias bajo el régimen de separación de bienes o, estando en sociedad conyugal no hay bienes que liquidar; no existen hijos o, si los tuvieron ya son mayores de edad sin necesidad de alimentos; $y$, ambos consortes se desarrollaron personal y profesionalmente, porque lo que tampoco se compromete mutuamente la obligación alimentaria. 
Pero el panorama cambia si el objeto de litigio además de la acción del divorcio se integra por la definición que deba hacerse de las consecuencias de dicha disolución. Aquí podríamos plantearnos diversos cuestionamientos, sobre todo si a la receta descrita añadimos otros ingredientes: el libre desarrollo de la personalidad y la continencia de la causa. Principalmente preguntémonos ¿resulta necesario que, en búsqueda de la unidad jurídica y por tanto de la indivisibilidad de la continencia de la causa, se obligue a una persona cuya voluntad es dejar de permanecer unida en matrimonio a otra, a estarlo? Podríamos pensar en varias respuestas, pero demos cuenta de la que el Primer Tribunal Colegiado en Materia Civil del Séptimo Circuito materializó en tres procedimientos vistos para resolver.

Los amparos directos 571/2017, 825/2017 y 269/2018 tuvieron como común denominador que, en primera instancia en un juicio ordinario civil, además del divorcio incausado, se demandaron otras prestaciones. En el proceso 571/2017, se demandó la cancelación de una pensión alimenticia definitiva (Primer Tribunal Colegiado de Circuito en Materia Civil del Séptimo Circuito, 2018a: 7); en el 825/2017, se requirió la desocupación material de un bien inmueble y la declaración judicial de la carencia sobre el derecho de propiedad respecto de ese bien (Primer Tribunal Colegiado de Circuito en Materia Civil del Séptimo Circuito, 2018b: 4); y, en el 269/2018, se alegó la liquidación de la sociedad conyugal (Primer Tribunal Colegiado de Circuito en Materia Civil del Séptimo Circuito, 2018c: 6 y 7). En los tres procedimientos, el juez de primera instancia resolvió de manera autónoma el divorcio incausado y reservó los derechos para continuar con la secuela procesal y pronunciarse ex post sobre el resto de las prestaciones (Primer Tribunal Colegiado de Circuito en Materia Civil del Séptimo Circuito, 2018a: 8; Primer Tribunal Colegiado de Circuito en Materia Civil del Séptimo Circuito, 2018b: 6 y 7; Primer Tribunal Colegiado de Circuito en Materia Civil del Séptimo Circuito, 2018c: 10).

Agotada la segunda instancia, cuyo contenido no trasciende para lo que aquí tratamos, se interpusieron los respectivos juicios de casación en contra de las Salas del Poder Judicial del Estado que conocieron de los asuntos. En ellos, el Primer Tribunal Colegiado estimó como una violación procesal que las autoridades responsables no se hubieran pronunciado sobre la división de la continencia de la causa que hizo el juez de primera instancia, por lo que ordenó dejar insubsistentes las sentencias de alzada y emitir nuevos fallos en los que se ordenara la reposición de los procedimientos civiles, hasta antes de las resoluciones que decidieron sobre el divorcio de manera autónoma (Primer Tribunal Colegiado de Circuito en Materia Civil del Séptimo Circuito, 2018a: 18; Primer Tribunal Colegiado de Circuito en Materia Civil del Séptimo Circuito, 2018b: 25; Primer Tribunal Colegiado de Circuito en Materia Civil del Séptimo Circuito, 2018c: 18 y 19).

En su labor de fundar y motivar las resoluciones, los magistrados del Tribunal Colegiado concluyeron en que:

- La sentencia, como acto jurídico de decisión, no puede declararse ejecutoriada en partes o en fracciones, sino que, con atención a la continencia de la causa, debe declararse en forma completa y total, esto es, por todas las acciones y excepciones que dieron origen a la sentencia (Primer Tribunal Colegiado de Circuito en Materia 
Civil del Séptimo Circuito, 2018a: 15; Primer Tribunal Colegiado de Circuito en Materia Civil del Séptimo Circuito, 2018b: 20; Primer Tribunal Colegiado de Circuito en Materia Civil del Séptimo Circuito, 2018c: 15 y 16).

- Que la resolución autónoma de la prestación de la disolución del vínculo matrimonial, fue una violación manifiesta a las leyes que rigen el procedimiento $y$, por tanto, ameritaba su reposición (Primer Tribunal Colegiado de Circuito en Materia Civil del Séptimo Circuito, 2018a: 16; Primer Tribunal Colegiado de Circuito en Materia Civil del Séptimo Circuito, 2018c: 16).

- Que la existencia de dos sentencias implicó violación a la unidad jurídica, por ser indivisible; que debe guardar coherencia interna y por ello no puede escindirse en el estudio de las acciones en dos resoluciones distintas (Primer Tribunal Colegiado de Circuito en Materia Civil del Séptimo Circuito, 2018a: 16; Primer Tribunal Colegiado de Circuito en Materia Civil del Séptimo Circuito, 2018b: 21; Primer Tribunal Colegiado de Circuito en Materia Civil del Séptimo Circuito, 2018c: 16).

- Que la sentencia definitiva al no comprender el estudio sobre la prestación de la disolución del vínculo matrimonial, violó el principio de congruencia, por no contener una decisión acorde a los puntos controvertidos, lo que provocó la existencia de dos sentencias de fondo (Primer Tribunal Colegiado de Circuito en Materia Civil del Séptimo Circuito, 2018a: 18; Primer Tribunal Colegiado de Circuito en Materia Civil del Séptimo Circuito, 2018b: 24; Primer Tribunal Colegiado de Circuito en Materia Civil del Séptimo Circuito, 2018c: 18).

Además, producto del criterio sostenido, el Tribunal Colegiado de Circuito de mérito publicó la siguiente tesis aislada:

DIVORCIO INCAUSADO. NO DEBE DECRETARSE EN EL TRÁMITE DEL JUICIO, EN FORMA AUTÓNOMA Y DEJARSE PENDIENTES PARA SU POSTERIOR RESOLUCIÓN LAS DEMÁS PRESTACIONES DERIVADAS DE LA DISOLUCIÓN DEL MATRIMONIO, PUES SE ROMPE CON EL PRINCIPIO DE CONTINENCIA DE LA CAUSA, ANTE LA EVENTUAL EXISTENCIA DE DOBLE SENTENCIA, CUANDO ÉSTA ES UNA UNIDAD INDIVISIBLE QUE DEBE GUARDAR COHERENCIA INTERNA Y, POR ELLO, NO PUEDE ESCINDIRSE EL ESTUDIO DE LAS ACCIONES EN DOS RESOLUCIONES DISTINTAS (LEGISLACIÓN DEL ESTADO DE VERACRUZ). Conforme a lo dispuesto en los artículos 516, 517, fracción I, 518 y 519 del Código de Procedimientos Civiles para el Estado de Veracruz, por regla general, si bien es cierto que el tribunal de apelación reasume jurisdicción en la medida de lo planteado en los agravios relativos, también lo es que debe subsanar las omisiones o incongruencias que haya cometido su inferior, ante la inexistencia del reenvío; de tal forma que el tribunal de alzada está facultado -mediante la apelación- para reparar los agravios ocasionados al inconforme y dictar un nuevo fallo que confirme, modifique o revoque la sentencia de primera instancia, pues el Juez al emitirla agotó la facultad que le confiere la ley de resolver el negocio; sobre todo en controversias en materia familiar, en las que el tribunal de alzada está obligado a suplir la queja deficiente atento a lo dispuesto en el numeral 514 del código procesal civil citado. Así, como la sentencia de segunda instancia sustituye procesalmente a la de primera, previo al pronunciamiento del fondo del asunto, el tribunal de apelación debe verificar si se encuentran satisfechos todos los presupuestos y elementos procesales necesarios para emitir una sentencia que dirima todos los puntos sujetos a debate, a fin de dictar un fallo congruente, como lo ordena el artículo 57 , primer párrafo, del código procesal invocado. Lo anterior, en relación con el diverso precepto 338, fracción IV,(1) del propio código, permite deducir que la sentencia, como acto jurídico de decisión, no puede declararse ejecutoriada en partes o en fracciones, sino que atendiendo al principio de "continencia de la causa", 
que consiste en la unidad que debe existir en todo juicio, debe declararse en forma total y completa, esto es, por todas las acciones y excepciones que dieron origen a dicha sentencia. En ese orden de ideas, si se recurre en apelación la sentencia de primera instancia, ello hace que quede sub júdice en su integridad, y el dictado de fondo que se emita debe comprender todas esas acciones y excepciones deducidas oportunamente en el juicio lo que, incluso, resulta acorde con lo dispuesto en el primer párrafo del artículo 157 del Código Civil para el Estado, en el sentido de que: "La sentencia de divorcio fijará en definitiva la situación de los hijos, para lo cual el Juez deberá resolver todo lo relativo a los derechos y obligaciones inherentes a la patria potestad, su pérdida, suspensión o limitación según el caso, y en especial a la custodia y al cuidado de los hijos."; por tanto, si el tribunal de alzada, al resolver la apelación decide lo relativo al derecho alimentario de la parte acreedora, pero pasa por alto que el Juez dividió la continencia de la causa, ya que en el curso del procedimiento decretó el divorcio incausado, en forma autónoma y dejó de resolver lo relativo a la cancelación o subsistencia del derecho alimentario de la parte demandada, siendo que ambas cuestiones debieron decidirse en el mismo fallo; por lo que esas omisiones del Juez inferior, ameritan que se subsanen, reasumiendo jurisdicción. Lo anterior, porque de lo contrario implicaría la eventual existencia de dos sentencias, cuando ésta es una unidad indivisible que debe guardar coherencia interna y, por ello, no puede escindirse el estudio de las acciones en dos resoluciones distintas. En esas condiciones, se transgrede el principio de congruencia establecido en el primer párrafo del artículo 57 citado, si la sentencia reclamada no contiene una decisión acorde con todos los puntos controvertidos, lo que provocará la existencia de doble sentencia de fondo; en contravención a los derechos fundamentales de legalidad y seguridad jurídica, consagrados en los artículos 14 y 16 de la Constitución Política de los Estados Unidos Mexicanos. (Tribunales Colegiados de Circuito, 2019: 5159)

Ahora bien, para imponernos sobre el criterio sostenido, debemos traer a colación ciertas premisas sine qua non. En primer término, subrayemos que en este asunto se ven inmiscuidos dos derechos: el derecho a la tutela jurisdiccional efectiva a través de la aplicación de la figura procesal de la continencia de la causa y, el derecho al libre desarrollo de la personalidad mediante la acción del divorcio incausado y su resolución de forma autónoma en un proceso en el que concurren varias de acciones entre los mismos litigantes. En segundo plano, retomemos nuestro cuestionamiento sobre si resulta necesario que, en búsqueda de la unidad jurídica y por tanto de la indivisibilidad de la continencia de la causa, se obligue a una persona cuya voluntad es dejar de permanecer unida en matrimonio a otra, a estarlo.

Comencemos definiendo que en la interpretación de la SCJN, el divorcio incausado, en las legislaciones en las cuales se ha reconocido, evita conflictos en el proceso de disolución del vínculo matrimonial que importen una afectación al desarrollo psicosocial de los integrantes de la familia, contribuyendo al bienestar de las personas y a su convivencia constructiva, respetando el libre desarrollo de la personalidad al dar preponderancia a la voluntad del individuo cuando ya no desea seguir vinculado a su cónyuge (Primera Sala de la SJCN, 2012:1200) y, en aquellas entidades federativas en las que no se ha normado y se sigue con la regulación de la acreditación de causales, el Máximo Tribunal se ha pronunciado sobre su inconstitucionalidad (Primera Sala de la SCJN, 2015: 570). Particularmente, advirtió en la resolución a la Contradicción de Tesis 73/2014 (Primera Sala de la SCJN, 2015), que:

- Se trata de una medida que interviene en el contenido prima facie del libre desarrollo de la personalidad porque supone la decisión de un cónyuge de no permanecer casado, independientemente de sus motivos, lo que significa parte del 
plan de vida que ha elegido, el cual no debe ser obstaculizado por el Estado ni por un tercero (: 30 y 31$)$;

- La medida legislativa de acreditación de causales no es idónea para alcanzar los fines que persiguen los límites externos del libre desarrollo de la personalidad, ni la protección de derechos de terceros, ni la protección del orden público (:32);

- Tampoco es una medida idónea para proteger la familia, porque el matrimonio no es la base del núcleo familiar que protege la CPEUM, al reconocer una pluralidad en su formación (: 33-35); y,

- La disolución del matrimonio sin causa, constituye un régimen de fácil acceso al divorcio, en el que basta la solicitud unilateral del cónyuge para que el juez la decrete, sin importar la oposición del diverso consorte (: 36).

Más que una colisión de derechos entre el de acceso a la justicia y el libre desarrollo de la personalidad, nos situamos en determinar la necesidad de que la indivisibilidad de la continencia de la causa permanezca incólume ante el requerimiento de satisfacción del libre desarrollo de la personalidad. Lo anterior lo consideramos así, porque la figura procesal de la continencia de la causa es un requisito de legalidad mientras que la protección del libre desarrollo de la personalidad es un mandato constitucional. El derecho de acceso a la justicia se protege mediante otras tantas instituciones, figuras procesales o lecturas de estas, que pudieran resultar menos lesivas al contenido de un derecho fundamental, como lo es el libre desarrollo de la personalidad.

Retrocedamos a nuestra afirmación de que el diseño arquitectónico procesal per se no redunda en inconstitucional, pero lo que sí pudiera resultar inconstitucional es la anteposición de una figura inexcusablemente a la garantía de un derecho autónomo. De esa forma, la incorporación de la continencia de la causa fortalece la seguridad jurídica, como mandato constitucional prevenido en los artículos 14 y 16 de la CPEUM, de ahí que esta regla procesal persiga fines legítimos amparados constitucionalmente. También podemos sostener que la medida es idónea para alcanzar los fines que abriga, porque a través de ella se impide que los justiciables resientan incertidumbre ante el eventual dictado de sentencias contradictorias respecto de una pluralidad de acciones con identidad de cosas y personas demandadas en un solo proceso, empero no resulta necesaria porque existen medidas alternativas a la regla procesal que instruye que la pluralidad de pretensiones con identidad de personas y cosas se persiga en un mismo juicio y se resuelvan en una sola sentencia.

La vista panorámica ofrecida sobre la aplicación forzosa y el quebrantamiento de la continencia de la causa nos permite sostener que, el juzgador, como rector del proceso, tiene facultades para adoptar su ejecución o no, ante las necesidades del juicio. Aparte, porque del andamiaje normativo que regula la acumulación de acciones y de autos, en Veracruz, no se desprende un mandato taxativo que orille al operador jurisdiccional a mantener indivisible el objeto del litigio siempre y sobre todas las cosas. Y, porque de la construcción jurisprudencial, se dispone la preferencia del resguardo de los principios y valores inmiscuidos en el proceso sobre una tramitación embarazosa que los sacrifique; 
criterio en armonía con la obligación constitucional de todas las autoridades, en el ámbito de sus competencias, de promover, proteger respetar y garantizar derechos humanos y acorde con el deber del Estado de remover, a través de sus operadores, en este caso los jueces, los obstáculos que administrativa o legislativamente impidan la satisfacción de un derecho.

Ante tales consideraciones, es perjudicial para la construcción del contenido del derecho al libre desarrollo de la personalidad que se anteponga para su ejercicio la continencia de la causa, porque el propio CPCV reconoce la posibilidad de ostentar pluralidad de sentencias que resuelvan los puntos controvertidos y no necesariamente reducirse a una sola.

La interpretación y aplicación del Primer Tribunal Colegiado en Materia Civil del Séptimo Circuito, es sumamente restrictiva y no se apega a la literalidad del marco regulatorio. Tal como vimos, en los artículos 56 -fracción I- y 57 de la normatividad adjetiva veracruzana, se detalla la existencia de varias sentencias y en ningún momento constriñe el hecho de que, cuando se experimente un asunto en el que el juez deba resolver sobre varias prestaciones, estas deban ser resueltas en una sola, sino que basta con que en el cúmulo de ellas se respondan a todos los puntos objeto de un solo litigio.

Por otro lado, la emisión de una sentencia definitiva autónoma que decida sobre el divorcio incausado y reserve para otras, posteriores, el resto de las prestaciones, no vulnera el principio de congruencia externa. Como prevenimos, el tratamiento de ese axioma debe ser reconfigurado hacia un repaso integral de todas las constancias -absolutamente todasque obren en el proceso y, entre ellas, las diversas sentencias definitivas que se hubieren dictado.

Bajo esa óptica, la idea de las sentencias definitivas debe alejarse de su graduación cuantitativa. Es decir, el calificativo de definitiva de la que es acreedora una sentencia, de ninguna manera significa que en el proceso exista una sola, porque ese lo dota la materialidad de esta, es decir, el significado que tiene para la secuela procesal (Primera Sala de la SCJN, 2013: 592; Primera Sala de la SCJN, 2020: 597). Dicho de otro modo, cuando hablamos de sentencias definitivas, poco importa cuántas se dicten en un proceso, sino que, para su obtención se hayan observado las formalidades del procedimiento y en ella se contenga la definición resolutoria del punto que, individual o como parte del objeto de litigio, se encuentre alegando. Sin dejar de observar que pudieran existir ocasiones en que por más que el juzgador quisiera, no pueda dividir la continencia de la causa, porque la resolución de una prestación impida el pronunciamiento de otras. Por ello, antes dijimos que ese aspecto procesal debe verse con lentes cualitativos y no cuantitativos, con índices epistémicos jurídicos.

Por esa razón, cuando tratamos del divorcio incausado, cuya finalidad es resolver la situación fáctica, de unión jurídica, entre dos personas unidas en matrimonio y, en la hipótesis de que en un mismo proceso se ventilen las consecuencias de esa disolución, es menester que se resuelva el estado del resto de las relaciones jurídicas familiares y patrimoniales. Sin embargo, la causa puede escindirse, para decidir autónomamente sobre la voluntad de uno de los consortes de no permanecer unido en matrimonio al otro, y dejar a salvo las demás prestaciones y derechos para ser ejercitados y resueltos en otras 
sentencias definitivas, porque la continencia de la causa no es una medida necesaria que pueda ni deba privilegiarse sobre el contenido del libre desarrollo de la personalidad, al ser este el basamento de la decisión, alternativa, de un cónyuge de no permanecer en el matrimonio y concretar así el modelo del proyecto de vida que ha decidido ejercitar.

\section{Conclusiones}

El ejercicio de cualquier derecho humano no es absoluto. Mediante la incorporación de la figura procesal de la continencia de la causa, el legislador ordinario protegió el derecho a la tutela jurisdiccional efectiva, pues a través de ella, se dota de certidumbre jurídica a los litigantes de evitar sentencias contradictorias cuando existen pluralidad de acciones con identidad de personas y cosas $y$, se economiza procesalmente el juicio. Empero su aplicación se encuentra sujeta a un criterio de necesidad. Esto es, con claridad es la regla general que debe ser leída en integralidad con sus excepciones.

Desde una primera óptica, la preservación de la continencia de la causa es una condición de seguridad para el colitigante de un proceso con múltiples acciones. Ahora, cuando se trata de un litigio compuesto, en el que una de las pretensiones es la acción del divorcio incausado, la aplicación de aquella figura debe ceder para que esta prestación sea resuelta de forma autónoma, en virtud de que mediante su interposición se concreta una decisión protegida constitucionalmente por el libre desarrollo de la personalidad, que supone diseñar el proyecto de vida soberanamente, sin injerencias de terceros ni del orden público.

Con la facultad de dirección que tiene el operador jurisdiccional, sus competencias para desplazar fundada y motivadamente las piezas del ajedrez denominado juicio y, la obligación de remover los obstáculos que impidan la garantía de un derecho humano, el criterio de que la continencia de la causa debe ser inexcusablemente aplicada, debe ser matizado. El propio CPCV no impide su división, así que el matiz proviene de la posibilidad de dictar diversas sentencias definitivas, incluso una por cada asunto principal controvertido, dado que el reduccionismo a una sola sentencia es un extremo procesal sin asidero legal ni constitucional. 


\section{Bibliografía}

\section{Fuentes de consulta}

Aguilera Portales, R. E. (2018). Concepto, fundamento y doctrina de los derechos humanos y libertades fundamentales en el sistema constitucional. En: R. Sánchez Vázquez (Coord.), Derechos humanos, seguridad humana, igualdad y equidad de género (pp. 187-202). México: CNDH.

Briseño García Carrillo, M. E. (2016). El derecho procedimental. En: M. E. Briseño García Carrillo y C. Gómez Fröde (Coords.), Nuevos paradigmas del derecho procesal (pp. 191-216). México: UNAM.

Eraña, M. (2014). El libre desarrollo de la personalidad en la legislación mexicana entendiendo su significado más allá de ser el bien protegible en delitos contra trata humana. En: J. Vega Gómez (Coord.), Temas selectos de derecho internacional privado y de derechos humanos. Estudios en homenaje a Sonia Rodríguez Jiménez (pp. 127-150). México: UNAM.

Flores Castillo, D. (2019). La jurisprudencia y su armonización en el contexto del divorcio sin expresión de causa. En: A. Guzmán Ávalos y M. del C. Valdés Martínez (Coords.), Construcción del derecho de familia (pp. 118-240). México: Tirant Lo Blanch.

García Máynez, E. (2008). Introducción al estudio del Derecho (60ạ ed.). México: Porrúa.

Hernández Cruz, A. (2018). Derecho al libre desarrollo de la personalidad. México: UNAM.

Jongitud Zamora, J. (2015). Introducción al Derecho (2a ed.). México: Universidad Veracruzana.

López Sánchez, R. (2019, enero-abril). La dignidad humana en México: su contenido esencial a partir de la jurisprudencia alemana y española. Boletín Mexicano de Derecho Comparado, Año LI. (154), 137-173.

Lozano Villegas, G. (2004). El libre desarrollo de la personalidad y cambio de sexo: el transexualismo. En: M. Carbonell (Coord.), Derecho Constitucional. Memoria del Congreso Internacional de Culturas y Sistemas Jurídicos Contemporáneos (pp. 619637). México: UNAM. 
Moral Ferrer, A. (enero-julio-diciembre, 2012). El libre desarrollo de la personalidad en la jurisprudencia constitucional colombiana. Cuestiones Jurídicas de la Universidad Rafael Urdaneta, vol. VI (2), 63-96.

Ovalle Favela, J. (1981). Estudios de Derecho Procesal. México: UNAM.

Rumoroso Rodríguez, J. A. (2013, enero). Las sentencias. Praxis de la Justicia Fiscal y Administrativa, año $V(1), 1-11$.

Silva Mesa, J. S. y Valls Hernández, S. A. (2014). Transexualidad y matrimonio y adopción por parejas del mismo sexo. Criterios de la Suprema Corte de Justicia de la Nación (2a ed.). México: Porrúa.

Vázquez, R. (2017). Derechos humanos. Una lectura igualitaria. México: UNAM.

Victoria Pellegrini, M. (2019). Divorcio incausado: estrategia legal para la pacificación familiar. En: A. Guzmán Ávalos y M. del C. Valdés Martínez (Coords.), Construcción del derecho de familia (pp. 34-58). México: Tirant Lo Blanch.

\section{Internetgrafía}

RAE. (2019). Unidad. [Archivo HTLM]. Recuperado de https://dle.rae.es/unidad

\section{Resoluciones en extenso}

Primera Sala de la SCJN. (2019). Contradicción de Tesis 104/2019 suscitada entre el Décimo Quinto Tribunal Colegiado en Materia Civil del Primer Circuito, en Pleno del Octavo Circuito y el Pleno del Trigésimo Circuito. Suprema Corte de Justicia de la Nación.

Primer Tribunal Colegiado en Materia Civil del Séptimo Circuito. (2018a). Amparo Directo: 571/2017. Tribunales Colegiados de Circuito.

Primer Tribunal Colegiado en Materia Civil del Séptimo Circuito. (2018b). Amparo Directo: 825/2017. Tribunales Colegiados de Circuito.

Primer Tribunal Colegiado en Materia Civil del Séptimo Circuito. (2018c). Amparo Directo: 269/2018. Tribunales Colegiados de Circuito.

ColDH. (2001). Caso "La Última Tentación de Cristo" (Olmedo Bustos y otros) Vs. Chile. Fondo, Reparaciones y Costas.

Primera Sala de la SCJN. (2009). Amparo Directo Civil 6/2008 relacionado con la Facultad de Atracción 3/2008-PS. Suprema Corte de Justicia de la Nación.

Primera Sala de la SCJN. (2015). Contradicción de Tesis 73/2014 entre las sustentadas por el Cuarto Tribunal Colegiado del Décimo Octavo Circuito y el Segundo Tribunal 
López I. y Zapata M. / La continencia de la causa vs. el libre desarrollo de la personalidad. El divorcio incausado en Veracruz

Colegiado de Circuito del Centro Auxiliar de la Cuarta Región. Suprema Corte de Justicia de la Nación.

\section{Jurisprudencia y tesis aisladas}

Pleno de la SCJN. Jurisprudencia P./J. 47/95. Diciembre de 1995.

Primera Sala de la SCJN. Jurisprudencia 1a./J. 1/2020 (10a.). Febrero de 2020.

Primera Sala de la SCJN. Jurisprudencia 1a./J. 10/2019 (10a.). Febrero de 2019.

Primera Sala de la SCJN. Jurisprudencia 1a./J. 103/2017 (10a.). Noviembre de 2017.

Primera Sala de la SCJN. Jurisprudencia 1a./J. 111/2012 (10a.). Febrero de 2013.

Primera Sala de la SCJN. Jurisprudencia 1a./J. 25/2019 (10a.). Marzo de 2019.

Primera Sala de la SCJN. Jurisprudencia 1a./J. 28/2015 (10a.). Julio de 2015.

Primera Sala de la SCJN. Jurisprudencia 1a./J. 28/2015 (10a.). Julio de 2015.

Primera Sala de la SCJN. Jurisprudencia 1a./J. 3/2019 (10a.). Febrero de 2019.

Primera Sala de la SCJN. Jurisprudencia 1a./J. 37/2016 (10a.). Agosto de 2016.

Primera Sala de la SCJN. Jurisprudencia 1a./J. 9/2019 (10a.). Febrero de 2019.

Primera Sala de la SCJN. Jurisprudencia 1a./J. 82/2017 (10a.). Octubre de 2017.

Primera Sala de la SCJN. Tesis aislada 1a. CCXXIX/2012 (10a.). Octubre de 2012.

Tribunales Colegiados de Circuito. Tesis aislada VII.10.C.55 C (10a.). Junio de 2019.

Tribunales Colegiados de Circuito. Tesis aislada XXI.20.12 K. Agosto de 1997.

\section{Legisgrafía}

Código Civil para el Estado de Veracruz de Ignacio de la Llave [CCV]. Artículos 75, 140 y 141. 15 de septiembre de 1932 (México).

Código de Procedimientos Civiles para el Estado de Veracruz [CPCV]. Artículos 4, 13, 20, 3, $21,56,57,60,338,342-A, 342-$, 342-C, 342-D, 342-E, 342-F, 342-G, 342-H, 342-I, 342-J, 342-K, 342-L y 342-LL. 13 de octubre de 1932 (México). 
López I. y Zapata M. / La continencia de la causa vs. el libre desarrollo de la personalidad. El divorcio incausado en Veracruz

Constitución Política de los Estados Unidos Mexicanos [CPEUM]. Artículos 1, 14 y 16.5 de febrero de 1917 (México). 